\title{
Antioxidant and anticancer activities of enzymatic eel (monopterus sp) protein hydrolysate as influenced by different molecular weight
}

\begin{abstract}
This study aims to investigate the antioxidant and anticancer properties of fractionated eel protein hydrolysate (EPH) as well as qualitatively determine its free fatty acids. The eel flesh was enzymatically hydrolyzed and fractionated through membrane filter $(10 \mathrm{kDa}, 5 \mathrm{kDa}$ and $3 \mathrm{kDa}$ ). The lipid peroxidation assays and mechanisms of antioxidant activity (reducing power, ferrous ion chelating activity and 1, 1-diphenylpicrylhydrazyl (DPPH) radical scavenging activity) of fractionated EPH were determined. The anticancer activity was determined by $3-$ 4, 5-dimethylthiazol-2-yl-2, 5-diphenyltetrazolium bromide (MTT) assay using MCF-7 cell lines. Free fatty acids in eel flesh and EPH were determined using gas chromatography. The results obtained showed that $3 \mathrm{kDa} E P H$ possessed the highest inhibition of lipid peroxidation, reducing power, DPPH scavenging activity and anticancer activity. Moreover, the changes of unsaturated fatty acids during hydrolysis process resulting in more stable hydrolysate towards oxidation. Based on the mechanisms of antioxidant activity conducted, this study found that the EPH had more ability as primary antioxidant than secondary antioxidant.
\end{abstract}

Keyword: Eel protein hydrolysate; Fractionation; Fatty acids; Antioxidant; Anticancer 